\title{
Biocontrole da podridão vermelha da raiz e promoção de crescimento da soja
}

\author{
Janaina Silva SARZI ${ }^{1 *}$, Juliane LUDWIG ${ }^{2}$, Jéssica Emília RABUSKE ${ }^{1}$, \\ Pâmela Pires FERST ${ }^{2}$, Jéssica MALESCKI ${ }^{2}$, Lucas WARPECHOWSKI ${ }^{2}$
}

\author{
${ }^{1}$ Universidade Federal de Santa Maria, Santa Maria, RS, Brasil. \\ ${ }^{2}$ Universidade Federal da Fronteira Sul, Cerro Largo, RS, Brasil. \\ *E-mail: janainasarzi@yahoo.com.br
}

\begin{abstract}
Recebido em junho/2018; Aceito em setembro/2019.
RESUMO: A soja é uma das principais culturas do agronegócio mundial, e o Brasil se destaca por ser um dos maiores produtores dessa leguminosa. As doenças, especialmente causadas por patógenos habitantes do solo interferem significativamente no desenvolvimento e produtividade da cultura, especialmente por serem de difícil controle. O objetivo desse trabalho foi avaliar o biocontrole de Fusarium solani agente causal da podridão vermelha da raiz na soja, por isolados de Trichoderma spp. Para isso, foi avaliado o efeito dos antagonistas in vitro sobre o patógeno, utilizando a técnica de cultivo pareado, e o potencial dos antagonistas em reduzir a severidade da doença causada por $F$. solani in vivo, por meio da inoculação do patógeno em sementes de milho e o tratamento do solo com os antagonistas. Pôde-se observar que dentre os isolados de Trichoderma spp., $T$. asperellum foi o mais eficiente em inibir o crescimento in vitro do patógeno. No ensaio in vivo, o uso de Trichoderma mostrou-se efetivo no controle da severidade da podridão vermelha da raiz na soja, sendo $T$. harzianum UFFS o mais eficiente na redução dos sintomas causados por $F$. solani, bem como, promover o crescimento de plantas de soja.
\end{abstract}

Palavras-chave: Glycine max; Fusarium solani; Trichoderma.

\section{Biocontrol of root red root and promotion of soybean growth}

\begin{abstract}
Soy is one of the main agribusiness crops worldwide, and Brazil stands out as one of the largest producers of this legume. Diseases, especially caused by soil-dwelling pathogens, significantly interfere in crop development and productivity, especially as they are difficult to control. The objective of this work was to evaluate the biocontrol of Fusarium solani causal agent of red root rot in soybean by isolates of Trichoderma spp. For this, the effect of in vitro antagonists on the pathogen, using the paired culture technique, and the potential of the antagonists in reducing the severity of the disease caused by $F$. solani in vivo, through the inoculation of the pathogen in seeds of corn and soil treatment with the antagonists. It was observed that among the isolates of Trichoderma spp., T. asperellum was the most efficient in inhibiting in vitro growth of the pathogen. In the in vivo test, the use of Trichoderma was effective in controlling the severity of red root rot in soybean, with $T$. harzianum UFFS being the most efficient in reducing the symptoms caused by $F$. solani, as well as promoting the growth of soybean plants.
\end{abstract}

Keywords: Glycine max; Fusarium solani; Trichoderma.

\section{INTRODUÇÃO}

A cultura da soja (Glycine max (L.) Merril) está difundida no mundo inteiro, tornando-se cada vez mais importante para a economia mundial. No Brasil, conquistou grande importância econômica, e hoje é a principal cultura do agronegócio brasileiro. Devido a sua expansão de cultivo a diversos ambientes, tornou-se alvo de uma ampla gama de patógenos, que podem atacar todos os estádios de desenvolvimento, fazendo das doenças um fator limitante ao rendimento produtivo da cultura (ÁVILA et al., 2013).

As doenças causadas por patógenos de solo são, em geral, as mais preocupantes, devido não haver uma forma de controle eficiente (PREISIGKE et al., 2017), pois muitos desses patógenos são capazes de formar estruturas especializadas de resistência, permitindo que os mesmos possam sobreviver no solo em condições adversas (ANGELOTTI; HAMADA, 2017).
Dentre os patógenos de solo, o gênero Fusarium é um dos principais causadores de perdas à cultura da soja, por ser capaz de provocar a morte das plantas e poder atacá-las desde a fase inicial do desenvolvimento (ITO, 2013). Devido as perdas econômicas geradas pelas doenças na cultura da soja, é necessária a realização do seu controle. Atualmente o controle químico é o mais utilizado, contudo há uma crescente preocupação quanto a toxidade desses produtos aos organismos benéficos presentes no ambiente e à saúde humana (GHINI, 2004), necessitando o estudo de métodos alternativos para o manejo desses patógenos.

Nesse contexto, o controle biológico vem mostrando grande potencial e, portanto, tornando-se alvo nos estudos dos fitopatologistas na seleção de organismos capazes de controlar enfermidades em plantas (ROMEIRO, 2007). Além da sua ação no biocontrole de patógenos, alguns desses organismos também possuem a capacidade de influenciar beneficamente o 
desenvolvimento das plantas, na germinação de sementes, emergência de plântulas, crescimento e produtividade de grãos (CHAGAS et al., 2017).

Alguns estudos relatam a efetividade da utilização de espécies de Trichoderma no controle de patógenos de solo (AMIRA et al., 2017; NASCIMENTO et al., 2016), porém pouco desenvolvidos na cultura da soja. Assim, objetivou-se através desse estudo, verificar o efeito da aplicação de diferentes isolados de Trichoderma spp. no biocontrole da podridão vermelha da raiz causada por Fusarium solani e na promoção de crescimento de plantas de soja.

\section{MATERIAL E MÉTODOS}

\subsection{Micro-organismos}

Para os ensaios foram utilizados dois isolados de Trichoderma provenientes de produtos comerciais, pertencentes às espécies Trichoderma harzianum e Trichoderma asperellum, e um isolado de solo rizosférico com cultivo de morango no município de Cerro Largo- RS, cuja espécie foi identificada como T. harzianum, e codificado $T$. harzianum UFFS. O isolado fitopatogênico utilizado foi o Fusarium solani disponível na coleção de fungos do laboratório de Fitossanidade da Universidade Federal da Fronteira Sul Campus Cerro Largo.

\subsection{Ação dos biocontroladores in vitro}

Para os ensaios in vitro foi utilizada a técnica de cultivo pareado (BELL et al., 1982). Para tanto, discos de micélio do fitopatógeno foram retirados de placas com 7 dias de crescimento e depositados a $1 \mathrm{~cm}$ da borda interna de outra placa de Petri contendo meio de cultura Batata-Dextrose- Ágar (BDA). As placas foram incubadas em $\mathrm{BOD}$ a $25^{\circ} \mathrm{C}$ por 24 horas, na ausência de luz. Decorrido esse período, foi feita a transferência, individual, de discos de mesmo diâmetro dos isolados de Trichoderma, colocando-os de forma oposta aos discos do patógeno. Em seguida, as placas foram mantidas a temperatura de $25^{\circ} \mathrm{C}$ por 5 dias com fotoperíodo de 12 horas.

Para as avaliações, foi adotado o critério de Bell et al. (1982), a partir de uma escala de notas que varia de 1 a 5 , onde 1- antagonista invadiu completamente a colônia do patógeno e cobriu toda a superfície do meio, 2- antagonista cresceu pelo menos dois terços da superfície do meio, 3- antagonista e patógeno colonizaram aproximadamente a metade da superfície do meio, 4- patógeno colonizou pelo menos dois terços da superfície do meio, resistindo a invasão do antagonista e, 5- patógeno invadiu completamente a colônia do antagonista, ocupando toda a superfície do meio.

$\mathrm{O}$ delineamento experimental utilizado foi o inteiramente casualizado com quatro repetições por tratamento, em que cada repetição foi composta por uma placa de Petri. Os dados de nota e crescimento médio diário (CMD) foram submetidos à análise de variância e as médias comparadas pelo teste de Scott-Knott a 5\% de probabilidade. Os dados de crescimento micelial do patógeno foram submetidos a análise de regressão para estimar a sua curva e equação.

\subsection{Ação dos biocontroladores in vivo}

Para obtenção do inóculo dos isolados de Trichoderma, seguiu-se a metodologia proposta por Carvalho et al. (2011a), onde, 3 discos de micélio mais meio de cultura foram retirados da zona de crescimento ativo de colonias com 7 dias e transferidos para frascos erlenmeyer de $250 \mathrm{~mL}$ contendo $15 \mathrm{~g}$ de arroz parboilizado previamente umedecido e autoclavado. Os frascos foram mantidos em BOD a $25^{\circ} \mathrm{C}$ e fotoperíodo de $12 \mathrm{~h}$ por 7 dias.

Posteriormente, vasos contendo $500 \mathrm{~g}$ de solo não esterilizado, como substrato, foram infestados com os isolados de Trichoderma, individualmente, de acordo com o que propôs Auler et al. (2013), utilizando 2,5 g de arroz colonizado, que foram incorporados uniformemente ao solo. Decorridas $24 \mathrm{~h}$, foram depositadas 3 sementes de soja da cultivar FUNDACEP 61 RR por vaso, e, quando estas estabilizaram sua emergência, foi feito o raleio deixando-se apenas 1 planta por vaso.

A inoculação de $F$. solani foi feita mediante a preparação prévia do inóculo em grãos de milho, onde estes permaneceram imersos em água destilada durante 12 horas e após o descarte do excesso de água, $150 \mathrm{~cm}^{3}$ desses grãos foram colocados em frascos erlenmeyer de $250 \mathrm{~mL}$ e autoclavados. Após o resfriamento, foram transferidos dez discos de micélio mais meio de cultura do fungo para cada frasco. A incubação ocorreu em BOD a $22^{\circ} \mathrm{C}$, com $12 \mathrm{~h}$ de luz por 15 dias. Para a inoculação, foi depositado um grão de milho colonizado junto à cova de semeadura a $5 \mathrm{~cm}$ de profundidade. A cova foi coberta com uma camada de $1 \mathrm{~cm}$ de solo e sobre esse foram depositadas as sementes de soja que foram cobertas com solo (KLINGELFUSS et al., 2007).

Os tratamentos foram: T1: inoculação de $F$. solani apenas; T2: inoculação de F. solani e Trichoderma harzianum; T3: inoculação de Trichoderma harzianum apenas; T4: inoculação de F. solani e Trichoderma harzianum UFFS; T5: inoculação de Trichoderma harzianum UFFS apenas; T6: inoculação de F. solani e Trichoderma asperellum; T7: inoculação de Trichoderma asperellum apenas; T8: Controle não inoculado.

As avaliações foram realizadas aos 15, 18, 22, 25, 30, 32, 37, 39, 44, 46 e 51 dias após a emergência (DAE), sendo avaliada a severidade da doença na parte aérea das plantas, considerando os sintomas de cada folíolo expandido separadamente, por meio de uma escala de notas de 1 a 5 adaptada de Huang; Hartman (1998) (Figura 1).

\section{RESULTADOS}

\subsection{Ensaio in vitro}

$\mathrm{Na}$ avaliação do crescimento dos micro-organismos pareados, a partir da escala de notas (Tabela 1), observou-se que o isolado de $T$. asperellum apresentou maior ação antagônica sobre o patógeno $F$. solani, diferindo dos demais isolados testados.

Tabela 1. Crescimento micelial diário (CMD) do patógeno e classificação do antagonismo de isolados de Trichoderma spp. sobre F. solani.

Table 1. Daily mycelial growth (DMG) of the pathogen and classification of the antagonism of Trichoderma spp. about $F$. solani. Médias seguidas pela mesma letra na coluna, não diferem ao nível de significância de $5 \%$ de probabilidade pelo teste de Scott-Knott. C. V: Coeficiente de variação.

\begin{tabular}{lcc}
\hline \multicolumn{1}{c}{ Tratamento } & $\begin{array}{c}\text { CMD } \\
\left(\mathrm{cm} \cdot \text { dia }^{-1}\right)\end{array}$ & $\begin{array}{c}\text { Escala de } \\
\text { notas de Bell } \\
\text { et al. }(1982)\end{array}$ \\
\hline F. solani & $0,51 \mathrm{~b}$ & - \\
F. solani $x$ T. harzianum UFFS & $0,42 \mathrm{a}$ & $3,00 \mathrm{~b}$ \\
F. solani $\mathrm{x}$ T. asperellum & $0,40 \mathrm{a}$ & $2,25 \mathrm{a}$ \\
F. solani $\mathrm{x}$ T. harzianum & $0,41 \mathrm{a}$ & $3,00 \mathrm{~b}$ \\
\hline \multicolumn{1}{c}{ CV $(\%)$} & 12,69 & 10,50 \\
\hline
\end{tabular}



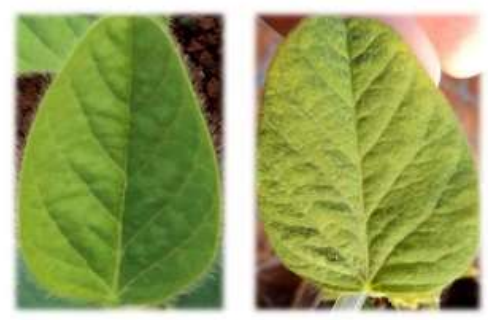

1 = ausência de sintomas 2 = leve desenvolviment dos sintomas com clorose afetada - afa)

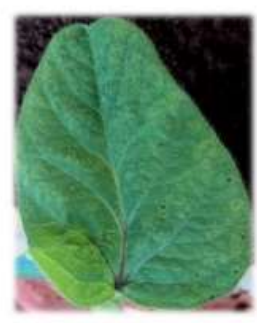

$3=$ desenvolvimento moderado dos sintomas com clorose internerval e necrose nas bordas foliares (11\%-30\% de afa e $(11 \%-30 \%$ de afa
necrose $\leq 10 \%$ )
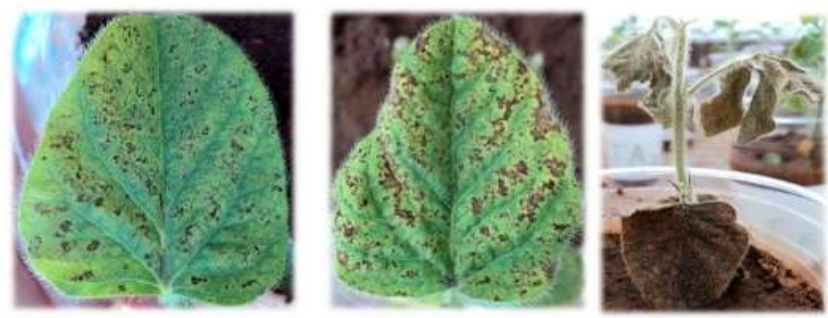

$\mathbf{4}=$ forte desenvolvimento dos $\mathbf{5}=$ severo desenvolvimento dos sintomas com clorose sintomas com clorose e necrose e necrose internerval e/ou plantas mortas $(>70 \%$ af: internerval $(31 \%-70 \%$ afa e $11 \%-30 \%$ de necrose) e necrose $>30 \%$ )

Figura 1. Escala de notas de 1 a 5 adaptada de Huang; Hartman (1998) para determinar a severidade da doença causada por $F$. solani em plantas de soja.

Figure 2. Scale of notes 1 to 5 adapted from Huang; Hartman (1998) to determine the severity of the disease caused by $F$. solani in soybean plants.

Observou-se também, que todos os isolados de Trichoderma foram capazes de interferir significativamente no crescimento micelial diário do patógeno quando comparado à testemunha (somente o patógeno), porém, sem diferir estatisticamente entre os isolados.

Nesse estudo, a ação dos dois isolados de T. harzianum sobre $F$. solani, receberam nota 3, que constitui a ocupação de $50 \%$ da placa pelo antagonista no último dia de confronto avaliado, enquanto o isolado de T. asperellum recebeu nota 2 , que representa a ocupação de dois terços da placa pelo antagonista.

Na curva e equação de regressão (Figura 2), observa-se uma tendência quadrática tanto para o crescimento do patógeno (testemunha) quanto para os tratamentos de confronto direto. Durante o confronto dos isolados de Trichoderma spp. e $F$. solani, o crescimento do patógeno foi permitido até as $24 \mathrm{~h}$ de incubação, onde o antagonista ainda não estava presente, após esse período, com a transferência dos discos dos isolados de Trichoderma spp., foi possível observar a redução da área colonizada pelo patógeno.

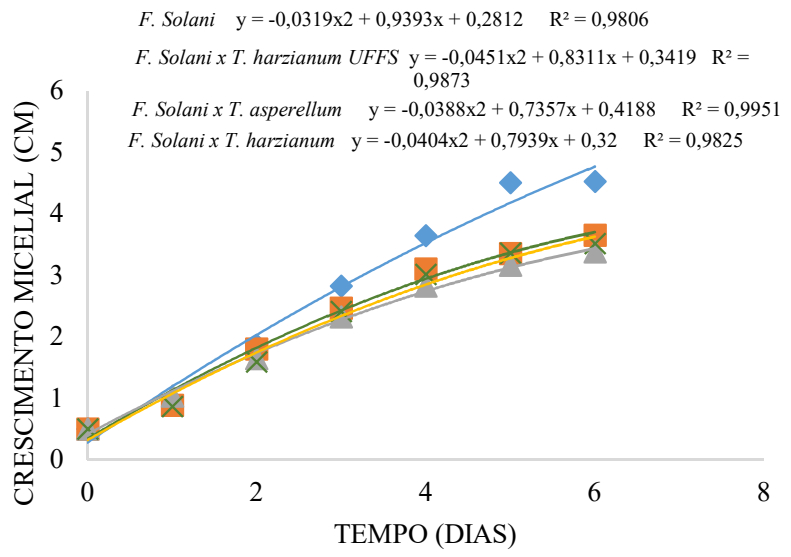

Figura 2. Curva e equação de regressão do cultivo pareado de Fusarium solani com isolados de Trichoderma spp. em diferentes tempos de incubação.

Figure 2. Curve and regression equation of Fusarium solani paired with Trichoderma spp. at different incubation times.

\subsection{Ensaio in vivo}

A severidade dos sintomas causados por $F$. solani, diferiu de acordo com os dias avaliados após a emergência. A porcentagem de incidência dos sintomas em cada avaliação foi influenciada pelo surgimento de novos trifólios, uma vez que cada folíolo e seu respectivo sintoma foi considerado em cada avaliação (Figura 3).

Nos tratamentos com inoculação de $F$. solani (Figura 3A), F. solani + T. harzianum (Figura 3C) e T. harzianum (Figura 3D) a nota mais frequente, em média, em toda a avaliação foi a 4. No tratamento com inoculação de $F$. solani a nota mais incidente foi a 4, ocorrida no trigésimo dia após a emergência (DAE), representando $100 \%$ da frequência. Para o tratamento com inoculação de $F$. solani $+T$. harzianum a nota mais expressiva foi a 5 no trigésimo DAE atingindo $100 \%$ de frequência.

No tratamento com inoculação de $T$. harzianum a nota 4 foi a mais incidente, representando $83,33 \%$ da frequência no vigésimo segundo e vigésimo quinto DAE.

Nos tratamentos com inoculação de $F$. solani (Figura 3A), F. solani + T. harzianum (Figura 3C) e T. harzianum (Figura 3D) a nota mais frequente, em média, em toda a avaliação foi a 4. No tratamento com inoculação de $F$. solani a nota mais incidente foi a 4, ocorrida no trigésimo dia após a emergência (DAE), representando $100 \%$ da requência. Para o tratamento com inoculação de $F$. solani $+T$. harzianum a nota mais expressiva foi a 5 no trigésimo DAE atingindo $100 \%$ de frequência. No tratamento com inoculação de T. harzianum a nota 4 foi a mais incidente, representando $83,33 \%$ da frequência no vigésimo segundo e vigésimo quinto DAE.

Nos tratamentos com inoculação de $F$. solani $+T$. harzianum UFFS (Figura 3E), T. harzianum UFFS (Figura $3 \mathrm{~F}$ ), T. asperellum (Figura $3 \mathrm{H}$ ) e o controle não inoculado (Figura 3B), a nota mais frequente, em média, foi a 3, porém, para o tratamento $F$. solani $+T$. harzianum UFFS a nota 1 foi a que atingiu maior incidência (100\%) no décimo quinto DAE. Para o tratamento com inoculação de $T$. harzianum UFFS, a nota 3 apresentou maior incidência $(83,87 \%)$ no trigésimo nono DAE. No tratamento com inoculação de T. asperellum, a nota 4 foi a que atingiu maior incidência, $62,5 \%$, no vigésimo segundo DAE, e, para o tratamento controle não inoculado, a nota 3 apresentou maior incidência (100\%) no décimo quinto DAE.

No tratamento com inoculação de $F$. solani $+T$. asperellum (Figura 3G), a nota com maior frequência foi a 5 e as notas com maior incidência foram a 4 no décimo oitavo DAE e a 5 no vigésimo quinto e trigésimo DAE com 100\% de frequência. Este tratamento, além de ser o único a apresentar maior frequência e maior incidência da nota máxima, foi o único a causar morte de uma planta. 
Na tabela 2 é possível observar que o tratamento $F$. solani $+T$. asperellum atingiu a maior frequência na nota 5 , diferenciando-se estatisticamente dos demais tratamentos, podendo-se concluir que este tratamento obteve sintomas mais severos em relação aos outros, concentrando a frequência da severidade dos sintomas nas notas 4 e 5 . Esse fato, também pode ser observado na porcentagem de incidência da doença, em que o tratamento $F$. solani $+T$. asperellum e $T$. asperellum, ambos inoculados com $T$. asperellum, tiveram todas as plantas com sintomas da doença aos 51 dias após a emergência.
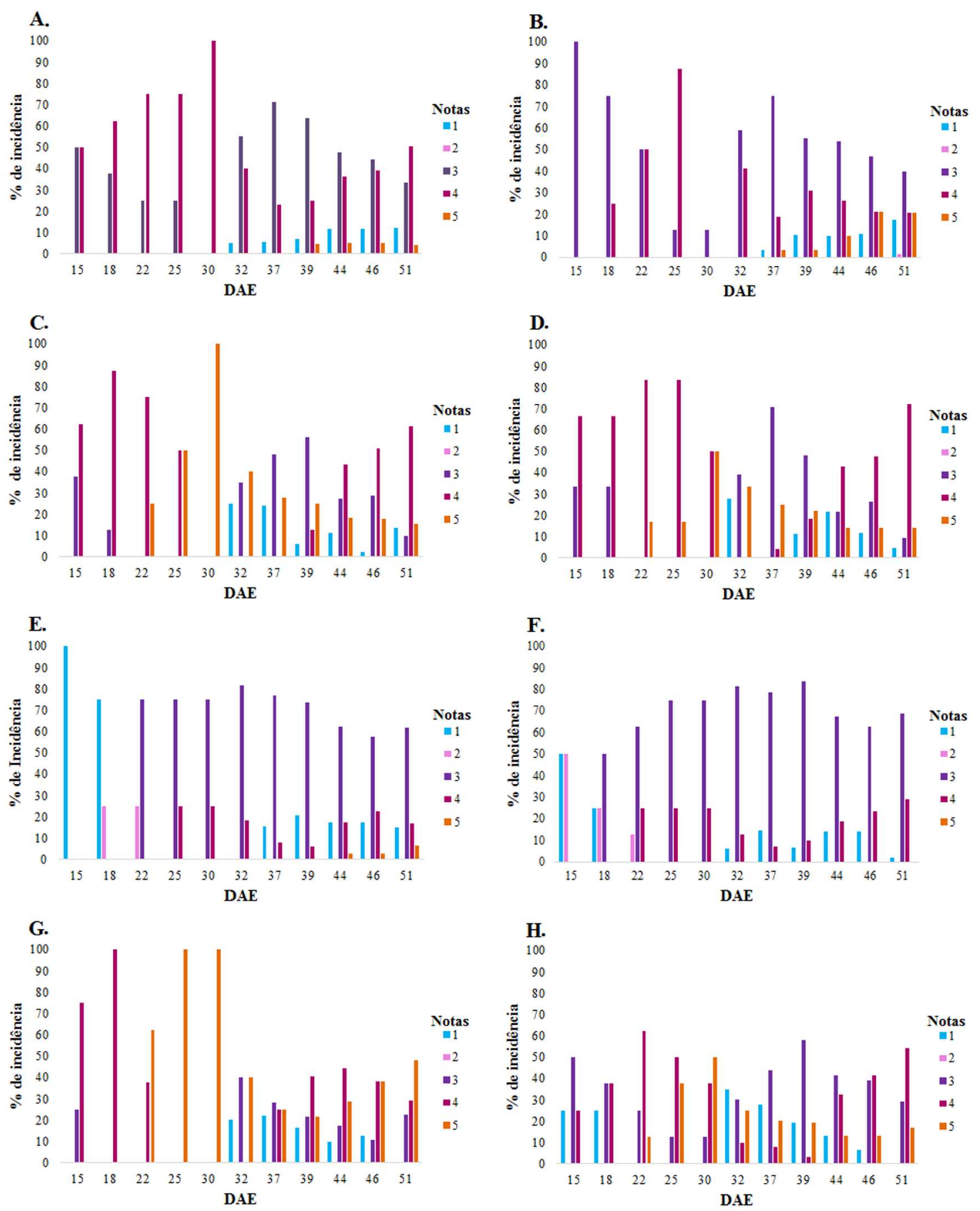

Figura 3. Distribuição da frequência das notas de severidade dos sintomas causados por $F$. solani na cultura da soja de acordo com a sua incidência em cada dia após a emergência. A: inoculação de $F$. solani apenas; B: Controle não inoculado; C: inoculação de $F$. solani e Trichoderma harzianum; D: inoculação de Trichoderma harzianum apenas; E: inoculação de F. solani e Trichoderma harzianum UFFS; F: inoculação de Trichoderma harzianum UFFS apenas; G: inoculação de F. solani e Trichoderma asperellum; H: inoculação de Trichoderma asperellum apenas.

Figure 3. Distribution of the frequency of symptoms severity scores caused by $F$. solani in soybean cultivation according to their incidence on each day after emergence. A: inoculation of $F$. solani only; B: Control not inoculated; C: inoculation of $F$. solani and Trichoderma harzianum; D: inoculation of Trichoderma harzianum only; E: inoculation of $F$. solani and Trichoderma harzianum UFFS; F: inoculation of Trichoderma harzianum UFFS only; G: inoculation of F. solani and Trichoderma asperellum; H: inoculation of Trichoderma asperellum only.

É possível que exista uma interação entre o isolado de $T$. asperellum e $F$. solani, uma vez que, se teve um aumento na

severidade da doença neste tratamento quando comparado aos tratamentos com inoculação de $F$. solani, T. asperellum e no 
controle não inoculado, não sendo indicado esse isolado para o controle de $F$. solani neste trabalho.

Dessa forma, observou-se que o tratamento com inoculação de $F$. solani $+T$. harzianum UFFS se mostrou o mais efetivo no controle de $F$. solani, principalmente quando comparado aos resultados obtidos no tratamento com inoculação de $F$. solani, no controle não inoculado, e até mesmo no tratamento com inoculação do $T$. harzianum proveniente de produto comercial.

$\mathrm{Na}$ massa seca de parte aérea, massa seca de radícula, estatura de parte aérea e comprimento de radícula, $T$. harzianum UFFS obteve as melhores médias em todas as variáveis, tanto isolado como associado ao patógeno, quando comparado aos demais tratamentos (Tabela 3). Além disso, o tratamento com inoculação de $F$. solani $+T$. harzianum UFFS mostrou-se superior ao tratamento $F$. solani na massa seca de radícula.

$\mathrm{O}$ isolado de $T$. asperellum não mostrou incremento em nenhuma variável avaliada em relação à testemunha, bem como quando combinado ao patógeno. Já o tratamento $T$. harzianum apresentou incremento apenas na estatura de parte aérea em relação à testemunha, porém, sem diferir estatisticamente.

Pode-se observar também que o tratamento com inoculação de $F$. solani apresentou maior estatura de parte aérea e comprimento de raiz em relação aos demais tratamentos, porém, na estatura diferiu estatisticamente apenas do tratamento $F$. solani $+T$. asperellum, e no comprimento de raiz dos tratamentos $T$. asperellum, $T$. harzianum, $F$. solani + T. asperellum e F. solani $+T$. harzianum.

Tabela 2. Frequência média de todos os dias avaliados após a emergência da severidade dos sintomas causados por $F$. solani na cultura da soja de acordo com a escala de notas e a incidência da doença aos 51 dias após a emergência.

Table 3. Average frequency of all evaluated days after emergence of the severity of the symptoms caused by $F$. solani in the soybean crop according to the grading scale and the incidence of the disease at 51 days after emergence.

\begin{tabular}{|c|c|c|c|c|c|c|}
\hline \multirow{2}{*}{ Tratamento } & \multicolumn{5}{|c|}{ NOTA } & \multirow{2}{*}{ Incidência (\%) } \\
\hline & 1 & 2 & 3 & 4 & 5 & \\
\hline F. solani & $4,28 \mathrm{a}$ & $0,00 \mathrm{a}$ & $40,88 \mathrm{a}$ & $53,35 \mathrm{~b}$ & $1,48 \mathrm{a}$ & $90,00 \mathrm{a}$ \\
\hline$F$. solani $+T$. harzianum & $7,12 \mathrm{a}$ & $0,00 \mathrm{a}$ & $23,26 \mathrm{a}$ & $40,47 \mathrm{~b}$ & $29,14 \mathrm{~b}$ & $88,39 \mathrm{a}$ \\
\hline T. harzianum & $6,21 \mathrm{a}$ & $0,00 \mathrm{a}$ & $27,61 \mathrm{a}$ & $49,22 \mathrm{~b}$ & $16,96 \mathrm{~b}$ & $96,67 \mathrm{~b}$ \\
\hline F. solani $+T$. harzianum UFFS & $23,03 \mathrm{~b}$ & $4,55 \mathrm{~b}$ & $58,62 \mathrm{~b}$ & $12,83 \mathrm{a}$ & $0,97 \mathrm{a}$ & $85,52 \mathrm{a}$ \\
\hline T. harzianum UFFS & $11,66 \mathrm{a}$ & $7,96 \mathrm{c}$ & $64,39 \mathrm{~b}$ & $16,00 \mathrm{a}$ & $0,00 \mathrm{a}$ & $97,73 \mathrm{~b}$ \\
\hline F. solani $+T$. asperellum & $7,03 \mathrm{a}$ & $0,00 \mathrm{a}$ & $14,83 \mathrm{a}$ & $35,23 \mathrm{~b}$ & $42,91 \mathrm{c}$ & $100,00 \mathrm{~b}$ \\
\hline T. asperellum & 13,83 a & $0,00 \mathrm{a}$ & $34,20 \mathrm{a}$ & $32,79 \mathrm{~b}$ & $19,17 \mathrm{~b}$ & $100,00 \mathrm{~b}$ \\
\hline Controle não inoculado & $4,92 \mathrm{a}$ & $0,12 \mathrm{a}$ & $51,12 \mathrm{~b}$ & $38,47 \mathrm{~b}$ & $5,36 \mathrm{a}$ & $83,36 \mathrm{a}$ \\
\hline CV $(\%)$ & 72,12 & $33,30^{1}$ & 36,57 & 43,95 & 52,49 & 8,74 \\
\hline
\end{tabular}

Médias seguidas pela mesma letra na coluna não diferem estatisticamente pelo teste de Scott-Knott a 5\% de probabilidade de erro. C. V: Coeficiente de variação. ${ }^{1}$ Dados transformados em $\sqrt{ } x+1 / 2$.

Tabela 4. Massa seca de parte aérea (MSPA) (g), massa seca de radícula (MSR) (g), estatura de parte aérea (EPA) (cm) e comprimento de raiz $(\mathrm{CR})(\mathrm{cm})$ de plantas de soja submetidas à diferentes inoculações, aos 51 dias após a emergência.

Table 3. Dry shoot mass (MSPA) (g), dry mass of radicle (MSR) (g), stature of aerial part (EPA)(cm) and root length (CR) (cm) of soybean plants submitted to different inoculations at 51 days after emergence.

\begin{tabular}{|c|c|c|c|c|}
\hline Tratamento & MSPA & MSR & EPA & $\mathrm{CR}$ \\
\hline F. solani & $0,51 \mathrm{a}$ & $0,26 \mathrm{~b}$ & $15,18 \mathrm{a}$ & $25,00 \mathrm{a}$ \\
\hline T. harzianum UFFS & $0,57 \mathrm{a}$ & $0,34 \mathrm{a}$ & $14,98 \mathrm{a}$ & $24,80 \mathrm{a}$ \\
\hline T. asperellum & $0,28 \mathrm{~b}$ & $0,11 \mathrm{c}$ & $13,52 \mathrm{a}$ & $16,98 \mathrm{~b}$ \\
\hline T. harzianum & $0,28 \mathrm{~b}$ & $0,09 \mathrm{c}$ & $14,68 \mathrm{a}$ & $15,38 \mathrm{~b}$ \\
\hline F. solani $+T$. harzianum UFFS & $0,50 \mathrm{a}$ & $0,30 \mathrm{a}$ & $14,17 \mathrm{a}$ & $23,90 \mathrm{a}$ \\
\hline F. solani $+T$. asperellum & $0,20 \mathrm{c}$ & $0,06 \mathrm{c}$ & $11,70 \mathrm{~b}$ & $11,70 \mathrm{~b}$ \\
\hline F. solani $+T$. harzianum & $0,17 \mathrm{c}$ & $0,05 \mathrm{c}$ & $13,52 \mathrm{a}$ & $12,62 b$ \\
\hline Controle não inoculado & $0,46 \mathrm{a}$ & $0,23 \mathrm{~b}$ & $14,48 \mathrm{a}$ & $24,92 \mathrm{a}$ \\
\hline CV (\%) & 16,51 & 21,44 & 8,28 & 16,09 \\
\hline
\end{tabular}

Médias seguidas com a mesma letra na coluna, não diferem ao nível de significância de 5\% de probabilidade pelo teste de Scott-Knott. C. V: Coeficiente de variação.

\section{DISCUSSÃO}

\subsection{Ensaio in vitro}

A eficiência de T. asperellum, já foi relatada em outros estudos, onde também apresentou bom potencial de antagonismo contra espécies de Fusarium (MILANESI, 2012). Além disso, o maior crescimento dessa espécie em relação aos patógenos, possivelmente é devido a melhor adequação desse isolado ao meio de cultura utilizado, uma vez, que esses são fatores determinantes para o crescimento de fungos, e a sua variação pode alterar de forma significativa o diâmetro das colônias (COSTA et al., 2015). Maciel et al. (2014), já haviam relatado o biocontrole de Trichoderma spp. sobre a espécie Fusarium sambucinum, onde a inibição do crescimento micelial do patógeno também se iniciou a partir de 24 horas de contato com o antagonista.

\subsection{Ensaio in vivo}

Pôde-se perceber, que mesmo os tratamentos onde não foi inoculado o patógeno, apresentaram sintomas da doença (Figura 3). Esse fato pode ser explicado, devido ao solo não ter passado pelo processo de esterilização e as sementes pelo processo de desinfestação, uma vez, que este patógeno e outros ocorrem de forma natural no solo podendo ser transmitidos tanto pelo solo, como via semente (ITO, 2013). 
Milanesi et al. (2013) observou que T. asperellum foi eficiente no controle de $F$. solani em soja, porém, comparado aos outros isolados de Trichoderma testados, apresentou maior tombamento de plântulas. No presente estudo, T. harzianum UFFS se mostrou mais eficiente no controle de $F$. solani provavelmente devido a este isolado já estar mais adaptado ao ambiente, sendo capaz de promover medidas mais eficientes de controle (GRIGOLETTI JUNIOR et al., 2000). A inoculação de T. harzianum em feijoeiro foi capaz de modular o metabolismo da cultura, desencadeando respostas de defesa e potencializando-as na presença de fungos fitopatogênicos $(R$. solani e $F$. solani), tanto de forma local como sistêmica na planta (PEREIRA et al., 2014). Bokhari; Perveen (2012), também comprovaram o potencial de $T$. harzianum em reduzir os danos provocados por $F$. solani na cultura do tomate, quando comparado às plantas inoculadas apenas com o patógeno, além, de ser eficaz na promoção do crescimento e maior massa seca das plantas.

Em relação a promoção de crescimento de plantas por Trichoderma, Carvalho et al. (2011b), evidenciaram efeito positivo de $T$. harzianum no desenvolvimento de parte aérea na cultura do feijoeiro em relação à testemunha absoluta. Santos (2008), explica que a ação de isolados de Trichoderma no incremento de parte aérea e radicular deriva de uma provável eficiência do isolado em se associar simbioticamente com as raízes da plântula, e, aliada à sua ação decompositora, libera os nutrientes prontamente absorvíveis para o vegetal. Este autor ainda complementa, que devido a capacidade de determinados isolados de Trichoderma em inibir a ação de fitopatógenos, previne que este cause qualquer tipo de interferência no desenvolvimento da plântula.

Em algumas variáveis, a combinação de Fusarium com as espécies de Trichoderma afetou negativamente o desenvolvimento das plantas, tanto em relação à testemunha como ao tratamento somente com inoculação de $F$. solani. Milanesi et al. (2013) justificam o efeito negativo na relação entre o patógeno e os isolados de Trichoderma, em função das possíveis relações antagônicas entre os metabólitos produzidos por ambos os fungos, refletindo diretamente no desenvolvimento das plantas tratadas com esses microorganismos.

Nesse estudo, as plantas de soja inoculadas com Fusarium spp. demonstraram maior crescimento do que as plantas não inoculadas, esse fato já foi relatado por outros autores como no trabalho desenvolvido por Ishikawa et al. (2018), em que, sementes de soja, cultivar BMX Elite, tratadas com Macrophomina phaseolina resultaram em plantas com maior altura comparado ao tratamento não inoculado. Esse fenômeno pode ser explicado, por as plantas apresentarem um tipo especial de resistência, chamada "escape", em que a planta atacada tem a capacidade de formar novas raízes em substituição aquelas destruídas pelo patógeno (BEDENDO, 2018). Algumas plantas apresentaram efeito negativo com o tratamento isolado de Trichoderma spp. Segundo Vinale et al. (2014), esse fato ocorre devido que em concentrações altas o micro-organismo pode ter ação inibitória no desenvolvimento da planta. Além disso, quando o Trichoderma está fora do seu habitat natural, que é o solo, pode agir como apodrecedor de sementes (ETHUR et al., 2012).

\section{CONCLUSÕES}

Com base nos resultados obtidos, pode-se indicar a utilização do isolado Trichoderma harzianum UFFS como uma forma alternativa e sustentável no controle de $F$. solani além de ser promotor de crescimento da cultura da soja.

\section{REFERÊNCIAS}

AMIRA, M. B.; LOPEZ, D.; MOHAMED, A. T.; KHOUAJA, A.; CHAAR, H.; FUMANAL, B.; GOUSSET-DUPONT, A.; BONHOMME, L.; LABEL, P.; GOUPIL, P.; RIBEIRO, S.; PUJADE-RENAUD, V.; JULIEN, J. L; AUGUIN, D.; VENISSE, J.-S. Beneficial effect of Trichoderma harzianum strain Ths97 in biocontrolling Fusarium solani causal agent of root rot disease in olive trees. Biological Control, Orlando, v. 110, p. 70-78, 2017. DOI: https://dx.doi.org/10.1016/j.biocontrol.2017.04.008

ANGELOTTI, F.; HAMADA, E. Efeito do déficit hídrico sobre a ocorrência de doenças de plantas. In: BETTIOL, W.; HAMADA, E.; ANGELOTTI, F.; AUAD, A. M.; GHINI, R. (Ed.). Aquecimento global e problemas fitossanitários. 1. ed. Brasília: Embrapa, 2017. p. 144158.

AUlER, A. C. V.; CARVAlHO, D. D. C.; MELlO, S. C. M. Antagonismo de Trichoderma harzianum a Sclerotium rolfsii nas culturas do feijoeiro e soja. Revista Agro@mbiente On-line, Boa Vista, v. 7, n. 3, p. 359-365, 2013. DOI: http://dx.doi.org/10.18227/19828470ragro.v7i3.1335

ÁVILA, C. J.; ROESE, A. D.; CONCENÇO, G.; RICHETTI, A.; GOULART, A. C. P. Manejo fitossanitário integrado na cultura da soja: uma solução sustentável. Dourados: Embrapa Agropecuária Oeste, 2013. 36 p. (Documentos Online, 119).

BEDENDO, I. P. Podridões de raiz e colo. In: AMORIM, L.; REZENDE, J. A. M.; BERGAMIN FILHO, A. (Ed). Manual de fitopatologia: Princípios e conceitos. 5. ed. Ouro Fino: Agronômica Ceres, 2018. v.1. p. 361-364.

BELL, D. K.; WELLS, H. D.; MARKHAM, C. R. In vitro antagonism of Trichoderma species against six fungal plant pathogens. Phytopathology, St. Paul, v. 72, n. 4, p. 379-382, 1982.

BOKHARI, N. A.; PERVEEN, K. Antagonistic action of Trichoderma harzianum and Trichoderma viride against Fusarium solani causing root rot of tomato. African Journal of Microbiology Research, v. 6, n. 44, p. 71937197, 2012.

CARVALHO, D. D. C.; MELlO, S. C. M. de; LOBO JUNIOR, M.; GERALDINE, A. M. Biocontrol of seed pathogens and growth promotion of common bean seedlings by Trichoderma harzianum. Pesquisa Agropecuária Brasileira, Brasília, v. 46, n. 8, p. 822-828, 2011a. http://dx.doi.org/10.1590/S0100204X2011000800006

CARVALHO, D. D. C.; MELLO, S. C. M.; LOBO JUNIOR, M.; SILVA, M. C. Controle de Fusarium oxysporum f. sp. Phaseoli in vitro e em sementes, e promoção do crescimento inicial do feijoeiro comum por Trichoderma harzianum. Tropical Plant Pathology, Brasília, v. 36, n. 1, 2011b. http://dx.doi.org/10.1590/S198256762011000100004

CHAGAS, L. F. B.; CHAGAS JUNIOR, A. F.; SOARES, L. P.; FIDELIS, R. R. Trichoderma na promoção do crescimento vegetal. Revista de Agricultura Neotropical, Cassilândia, v. 4, n. 3, p. 97-102, 2017. DOI: https://dx.doi.org/10.32404/rean.v4i3.1529 
COSTA, T. M.; SPERB, J. G. C.; RONCHETI, A. L.; BOTELHO, T. K. R.; SELL, T. M.; BERTOLI, S. L.; TAVARES, L. B. B. Avaliação da velocidade específica de crescimento radial de fungos em óleo vegetal residual. Revista de estudos ambientais, Blumenau, v. 17, n. 2, p. 29-40, jul./dez. $2015 . \quad$ DOI: http://dx.doi.org/10.7867/1983-1501.2015v17n2p29-40

ETHUR, L. Z.; BLUME, E.; LUPATINI, M.; MUNIZ, M. F. B.; ANTONIOLLI, Z. I.; LORENTZ, L. H. Trichoderma asperellum na produção de mudas contra a fusariose do pepineiro. Scientia Agraria Paranaensis, Marechal Cândido Rondon, v. 11, n. 4, p. 73-84, 2012.

GHINI, R. Coletor solar para a desinfestação de substratos para a produção de mudas sadias. Jaguariúna: Embrapa Meio Ambiente, 2004. 5 p. (Circular Técnica, 4).

GRIGOLETTI JUNIOR, A.; SANTOS, A. F. dos; AUER, C. G. Perspectivas do uso do controle biológico contra doenças florestais. Floresta, Curitiba, v. 30, n. 1/2, p. 155165, 2000. http://dx.doi.org/10.5380/rf.v30i12.2362

HUANG, Y. H.; HARTMAN, G. L. Reaction of selected soybean genotypes to isolates of Fusarium solani f. sp. glycines and their culture filtrates. Plant Disease, Saint Paul, v. 82, p. 999-1002, 1998. https://dx.doi.org/10.1094/PDIS.1998.82.9.999

ISHIKAWA, M. S.; RIBEIRO, N. R.; OLIVEIRA, E. C.; ALMEIDA, A. A.; BALBI-PEÑA, M. I. Seleção de cultivares de soja para resistência à podridão negra da raiz (Macrophomina phaseolina). Summa Phytopathologica, Botucatu, v. 44, n. 1, p. 38-44, 2018. http://dx.doi.org/10.1590/0100-5405/178653

ITO, M. F. Principais doenças da cultura da soja e manejo integrado. Nucleus, São Paulo, v. 10, n. 3, 2013. DOI: http://dx.doi.org/10.3738/nucleus.v0i0.908

KLINGELFUSS, L. H.; YORINORI, J. T.; DESTRO, D. Métodos de inoculação para quantificação de resistência em soja a Fusarium solani f. sp. glycines, em casa-devegetação. Fitopatologia brasileira, Brasília, v. 32 n. 1, p. 50-55, 2007. http://dx.doi.org/10.1590/S0100 41582007000100007

MACIEL, C. G.; WALKER, C.; MUNIZ, M. F. B.; ARAUJO, M. M. Antagonismo de Trichoderma spp. e Bacillus subtilis (UFV3918) a Fusarium sambucinum em Pinus elliottii engelm. Revista Árvore, Viçosa, v. 38, n. 3, p. 505-512, 2014. http://dx.doi.org/10.1590/S010067622014000300013

MILANESI, P. M. Aspectos biológicos da interação Fusarium spp. e Trichoderma spp. em solo compactado de aveia preta e soja sob plantio direto. 2012. 131f. Tese (Doutorado) - Universidade Federal de Santa Maria, Santa Maria, 2012.

MILANESI, P. M.; BLUME, E.; ANTONIOLI, Z. I.; MUNIZ, M. F. B.; SANTOS, R. F.; FINGER, G.; DURIGON, M. R. Biocontrole de Fusarium spp. com Trichoderma spp. e promoção de crescimento em plântulas de soja. Revista de Ciências Agrárias, Lisboa, v. 36, n. 3, p. 347-356, 2013.

NASCIMENTO, S. R. C.; SILVA, F. H. A.; CRUZ, B. L. S.; DANTAS, A. M. M.; AMBRÓSIO, M. M. Q.; SENHOR, R. F. Sobrevivência de estrutura de resistência de Macrophomina phaseolina e Sclerotium rolfsii em solo tratado biologicamente. Revista Agro@mbiente On-line, Boa Vista, v. 10. n. 1, p. 50-56, 2016. DOI: http://dx.doi.org/10.18227/1982-8470ragro.v10i1.2947
PEREIRA, J. L.; QUEIROZ, R. M.; CHARNEAU, S. O.; FELIX, C. R.; RICART, C. A.; SILVA, F. L. da; STEINDORFF, A. S.; ULHOA, C. J.; NORONHA, E. F. Analysis of Phaseolus vulgaris response to its association with Trichoderma harzianum (ALL-42) in the presence or absence of the phytopathogenic fungi Rhizoctonia solani and Fusarium solani. Plos one, v. 9, n. 5, 2014. DOI: https://dx.doi.org/10.1371/journal.pone.0098234

PREISIGKE, S. da C.; SILVA, L. P. da; SERAFIM, M. E.; BRUCKNER, C. H.; ARAÚJO, K. L.; NEVES, L. G. Early selection of Passiflora species resistant to fusariosis. Summa Phytopathologica, Botucatu, v. 43, n. 4, p. 321325, 2017. DOI: http://dx.doi.org/10.1590/0100$5405 / 175390$

ROMEIRO, R. da S. Controle Biológico de Doenças de Plantas: Fundamentos. Viçosa, 2007. 269 p.

SANTOS, H. A. dos. Trichoderma spp. como promotores de crescimento em plantas e como antagonistas a Fusarium oxysporum. 2008. 89f. Dissertação (Mestrado) - Universidade de Brasília, Faculdade de Agronomia e Medicina Veterinária, 2008.

VINALE, F.; SIVASITHAMPARAM, K.; GHISALBERTI, E. L.; WOO, S. L.; NIGRO, M.; MARRA, R.; LOMBARDI, N.; PASCALE, A.; RUOCOO, M.; LANZUISE, S.; MAGANIELLO, G.; LORITO, M. Trichoderma secondary metabolites active on plants and fungal pathogens. The Open Mycology Journal, v. 8, n. 1 p. $\quad 127-139, \quad 2014 . \quad$ DOI: http://dx.doi.org/10.2174/1874437001408010127 